\title{
Estimativa das Frações dos Carboidratos, da Casca e Polpa Desidratada de Café (Coffea arabica L.) Armazenadas em Diferentes Períodos ${ }^{1}$
}

\section{Adauto Ferreira Barcelos ${ }^{2}$, Paulo César de Aguiar Paiva ${ }^{3}$, Juan Ramón Olalquialga Pérez ${ }^{4}$, Roberto Maciel Cardoso ${ }^{5}$, Vander Bruno dos Santos ${ }^{6}$}

\begin{abstract}
RESUMO - O objetivo do experimento foi estimar as frações $\mathrm{A}, \mathrm{B}_{1}, \mathrm{~B}_{2}$ e $\mathrm{C}$ dos carboidratos da casca e da polpa desidratada das cultivares de café Catuaí, Rubi e Mundo Novo. A polpa foi obtida pela despolpa úmida em despolpador mecânico e, em seguida, seca ao sol até $13 \%$ de umidade. Os materiais foram armazenados em sacos de ráfia em ambiente coberto, ventilado e seco, com amostragem em triplicata a cada 90 dias. As frações foram determinadas conforme descrito no modelo do CNCPS. Houve acréscimo no teor das frações $\mathrm{A}$ e $\mathrm{B}_{1}$ e redução nas frações $\mathrm{B}_{2}$ e $\mathrm{C}$, à medida que se aumentou o tempo de armazenamento. A cultivar Catuaí, apresentou maior valor para a fração A, comparada a Rubi e Mundo Novo. Essa diferença chegou a 28\%, em relação a Mundo Novo. A fração $B_{1}$ foi maior nas cultivares Catuaí e Rubi, comparada a Mundo Novo. A cultivar Mundo Novo apresentou maior valor para a fração $B_{2}$ comparada às cultivares Catuaí e Rubi. Não foi encontrada diferença significativa entre as cultivares na fração C. A casca de café apresentou maior valor para as frações $\mathrm{A}_{\text {e }} \mathrm{B}_{1}$ e menor para a fração $\mathrm{B}_{2}$ comparada à polpa desidratada, ao passo que a fração $\mathrm{C}$ foi maior na polpa em comparação à casca de café. $\mathrm{O}$ armazenamento por doze meses alterou a proporção dos carboidratos, reduzindo as frações de degradabilidade lenta e não degradável, em detrimento da fração de degradabilidade rápida. A casca e polpa são materiais com alta proporção de carboidratos indisponíveis, o que pode limitar a sua utilização em grandes quantidades para os ruminantes.
\end{abstract}

Palavras-chave: carboidratos solúveis, carboidrato não-degradável, CNCPS, casca de café, polpa de café, resíduo agrícola

\section{Estimate of the Carbohydrate Fractions of the Coffee Hulls and Dehydrated Pulp of Coffee (Coffea arabica L.) Stored for Different Period}

\begin{abstract}
The coffee hull and pulp dehydrated carbohydrate fractions A, $\mathrm{B}_{1}, \mathrm{~B}_{2}$ and C, were evaluated according to the CNCPS. Three coffee cultivars were evaluated: Catuaí, Rubi and Mundo Novo. Pulp was obtained by moist pulping in a mechanical pulper and dried in the sun adjusted to $13 \%$ moisture. Materials were stored in raffia bags in environment free of moisture and well ventilated. Samplings were taken every 90 days. The equations utilized for determining fractions were reported in the CNCPS model. There was an increase in the fraction $A$ and $B_{1}$ content and reductions in fractions $B_{2}$ and $C$ as the storage time increased. The Catuaí cultivar presented a higher fraction A value, compared to Rubi and Mundo Novo. Fraction $\mathrm{B}_{1}$ was greater in the cultivars Catuaí and Rubi compared to Mundo Novo. The cultivar Mundo Novo presented higher value for fraction $\mathrm{B}_{2}$ compared to the cultivars Catuaí and Rubi. No significant differences were found among the cultivars for fraction $\mathrm{C}$. Coffee hull presented higher values for fractions $\mathrm{A}_{\text {and }} \mathrm{B}_{1}$ and lower for fraction $\mathrm{B}_{2}$ compared to dehydrated pulp, whilst fraction $\mathrm{C}$ was greater in the pulp as compared with coffee hull. The storage for 12 months changed the ratio of the carbohydrates, reducing the slow degradability and undegradable fractions and increasing the fast degradability fractions. Pulping process reduces sugars and pectin. Hull and pulp are materials with a high ratio of unavailable carbohydrates, which may limit its use in great amounts for ruminants.
\end{abstract}

Key Words: soluble carbohydrate, undegradable carbohydrate, coffee hull, coffee pulp, agricultural residue

\section{Introdução}

Os atuais conceitos de nutrição de ruminantes envolvem modelos que estimam a degradação dos alimentos no rúmen. Essa proposta tem levado os nutricionistas a buscarem alternativas para reduzir custos com a experimentação e definirem métodos para a formulação de dietas com maior segurança. Um sistema bastante promissor, de aplicação prática e com boa aceitação na comunidade científica é o sistema proposto por SNIFFEN et al. (1992), denominado Cornell Net Carbohydrate and Protein System (CNCPS).

\footnotetext{
1 Parte da tese de doutorado apresentada à UFLA-DZO pelo primeiro autor. Apoio financeiro da FAPEMIG.

2 Pesquisador da EPAMIG/CTSM, C.P. 176 - 37200-000 - Lavras, MG. E.mail: barcelos@ufla.br

3 Professor titular do Departamento de Zootecnia da UFLA, bolsista do CNPq. E.mail: pcapaiva@ufla.br

4 Professor titular do Departamento de Zootecnia da UFLA, bolsista do CNPq. E.mail: jroperez@ufla.br

5 Professor aposentado da Universidade Federal de Viçosa.

${ }^{6}$ Aluno do curso de Zootecnia da UFLA-DZO, bolsista do PIBIC/CNPq.
} 
Informações sobre o alimento no que diz respeito às frações e degradabilidade, mesmo que por estimativa, ajudam na sua avaliação para alimentação de ruminantes. A identificação e classificação de diferentes componentes da fração carboidrato e a relação com sua disponibilidade tornaram-se possíveis em decorrência do desenvolvimento dos sistemas de análises de alimentos baseados na solubilidade das frações em soluções detergentes.

A disponibilidade de resíduos agrícolas que podem ser avaliados para alimentação de ruminantes é grande. A casca de café devido à sua disponibilidade nos Estados e regiões produtoras de café é um destes materiais. Na safra de 99/2000 o Brasil produziu 27,1 milhões e Minas Gerais 14,3 milhões de sacas de café beneficiado (FLORIANI, 2000). Esta produção gerou, respectivamente, 1,626 milhões e 858 mil toneladas de casca de café, considerando a relação de café beneficiado:casca de 1:1 (BARTHOLO et al., 1989). No entanto não existe no Brasil estimativa da produção de polpa de café, mas observa-se que já é significativa a produção deste material decorrente do aumento da produção do café despolpado.

A maneira econômica de avaliar o potencial destes materiais seria a utilização de modelos que estimam as frações degradadas e não degradadas do alimento no rúmen. Normalmente esses subprodutos são pobres em proteína e ricos em fibra; as estimativas das frações dos carboidratos, seriam importantes para se avaliar o potencial dos resíduos como alimento para ruminantes.

O Cornell Net Carbohydrate and Protein System (CNCPS), sistema utilizado na avaliação de alimentos para ruminantes, determinando os teores de carboidrato e proteína líquidos, é definido como um sistema de contabilidade nutricional, planejado para estimar exigências nutricionais e a utilização da energia e da proteína dos alimentos, para combinações específicas entre tipos de bovinos, alimentos e condições de ambiente e manejo (PEREIRA et al., 1997). O sistema surgiu para prever o desempenho animal com base na composição dos alimentos, na taxa de passagem e degradação das fontes de energia e nitrogênio, na função ruminal, naingestão e nas exigências nutricionais (ROSSI JR. et al., 1997b).

O sistema trabalha com estimativas, utilizando dados das análises químicas realizadas no laboratório. Dados os valores de PB, gordura e cinza do alimento, expressos em \% da MS o conteúdo de carboidrato total (CHOt) pode ser estimado calculando-se a diferença entre $(\mathrm{CHOt}=100$ - $\mathrm{PB}-\mathrm{EE}-$ cinza $)$.
Os carboidratos podem ser classificados de acordo com a taxa de degradação em fração $\mathrm{A}$, rapidamente degradável (açúcares); fração $\mathrm{B}_{1}$, degradação intermediária (amido); fração $\mathrm{B}_{2}$, degradação lenta (parede celular disponível) e fração $C$, não degradável (parede celular indisponível). Essas frações são computadas do alimento, como carboidratos não estruturais (CNE), carboidratos estruturais (CE) e fibra indigestível (C) (SNIFFEN et al., 1992).

Os CNE contêm açúcares (fração A), amido e pectina (fração $B_{1}$ ), enquanto a fração $C E$ representa os $\mathrm{CHO}$ insolúveis em detergente neutro. Os $\mathrm{CE}$ podem ser estimados como 100 - (PB + FDN corrigida para proteína + lipídeos + cinza no alimento) (SNIFFEN et al., 1992).

O modelo de Cornell tem sido avaliado por alguns pesquisadores, como ROSSI JR. et al. (1997a), ROSSI JR. et al. (1997b), PEREIRA, BOSE e BOIN (1997a) e PEREIRA, BOSE e BOIN (1997b), os quais afirmam ser necessário maior número de dados para ajuste do modelo, para os alimentos e condições brasileiras.

O objetivo deste estudo foi avaliar a casca e polpa desidratada, das cultivares de café Catuaí, Rubi e Mundo Novo, armazenadas durante 12 meses, quanto às frações de carboidratos.

\section{Material e Métodos}

O experimento foi conduzido no Laboratório de Nutrição Animal do Departamento de Zootecnia da Universidade Federal de Lavras e Laboratório de Qualidade do Café Dr. Alcides de Carvalho do CTSM, da EPAMIG, no município de Lavras, no período de outubro de 1997 a dezembro de 1998.

Foram utilizadas casca e polpa desidratada das cultivares de café Catuaí vermelho IAC2077-2-5-99, Rubi MG1192 e Mundo Novo IAC379-19, provenientes da Fazenda Experimental de São Sebastião do Paraíso, da EPAMIG.

A casca foi obtida da limpeza do café em coco por cultivar; a polpa foi obtida também por cultivar, pela despolpa úmida, utilizando-se de despolpador DC3 e degomado no degomador mecânico DM2, ambos Pinhalense ${ }^{\circledR}$ e, em seguida, seca ao sol até $13 \%$ de umidade.

Tanto a casca quanto polpa foram armazenadas em sacos de ráfia, em ambiente coberto, ventilado e seco, por um ano. Neste período foram coletadas amostras em triplicata, a cada 90 dias, para análises 
bromatológicas.

As amostras foram pré-secas em estufa a $65^{\circ} \mathrm{C}$ com ventilação até alcançar peso constante, o que ocorreu entre 36 e 48 horas, e depois moídas em peneira de $2 \mathrm{~mm}$.

O delineamento experimental utilizado foi o inteiramente casualizado com três repetições, em esquema fatorial $3 \times 2 \times 5$ (cultivar $x$ material $\mathrm{x}$ armazenamento). O período de armazenamento foi de $0,90,180,270$, e 360 dias, conforme modelo estatístico a seguir:

$$
Y_{i j k l}=\mu+C_{i}+M_{j}+P_{k}+C M_{i j}+C P_{i k}+M P_{j k}+C M P_{i j k}+e_{i j k l}
$$
em que: $\mathrm{Y}_{\mathrm{ijkl}}=$ observação referente a cultivar i do material $\mathrm{j}$ no tempo $\mathrm{k}$ e repetição $1 ; \mu=$ média geral; $\mathrm{C}_{\mathrm{i}}=$ efeito da variedade, sendo $\mathrm{i}=1$ a $3 ; \mathrm{M}_{\mathrm{j}}=$ efeito de material, sendo $\mathrm{j}=1 \mathrm{a} 2 ; \mathrm{P}_{\mathrm{k}}=$ efeito do período de armazenamento, sendo $\mathrm{k}=1$ a $5 ; \mathrm{CM}_{\mathrm{ij}}=$ efeito da interação de cultivar i e material $\mathrm{j} ; \mathrm{CP}_{\mathrm{jk}}=$ efeito da interação cultivar i e período de armazenamento k; $\mathrm{MP}_{\mathrm{jk}}=$ efeito da interação material $\mathrm{j}$ e período de armazenamento $\mathrm{k} ; \mathrm{CMP}_{\mathrm{ijk}}=$ efeito da interação cultivar i, material j e período de armazenamento k; $\mathrm{e}_{\mathrm{ijkl}}=$ erro aleatório associado a cada observação, sendo $1=1$ a 3 .

Os dados foram analisados utilizando-se pacote estatístico Sistema de Análise de Variância para Dados Balanceados - Sisvar, segundo FERREIRA (2000) e as médias comparadas pelo teste de SCOTT e KNOTT (1974).

Neste trabalho, avaliaram-se, na casca e na polpa desidratada das três cultivares de café, as frações $\mathrm{A}, \mathrm{B}_{1}$, $\mathrm{B}_{2}$ e $\mathrm{C}$ de carboidratos segundo SNIFFEN et al. (1992).

As equações utilizadas para determinação das frações foram as seguintes, adaptadas de SNIFFEN et al. (1992).

$$
\begin{aligned}
& C H O(\% M S)=100-P B(\% M S)-E E(\% M S)-C I N Z A S(\% M S) \\
& C C(\% C H O)=100 \times\left(\frac{(F D N(\% M S) \times 0,01 \times L I G N I N A(\% F D N) \times 2,4}{C H O(\% M S)}\right) \\
& C B 2 \% C H O)=100 \times\left(\frac{(F D N(\% M S)-P I D N(\% P B) \times 0,01 \times P B(\% M S)-F D N(\% M S) \times 0,01 \times L I G N I N A(\% F D N)) \times 2,4}{C H O(\% M S)}\right) \\
& C B 1(\% C H O)=\left(\frac{A M I D O(\% C N E) \times(100-B 2(\% C H O)-C(\% C H O))}{100}\right) \\
& C A(\% C H O)=\left(\frac{(100-A M I D O(\% C N E)) \times(100-B 2(\% C H O)-C(\% C H O)}{100}\right)
\end{aligned}
$$

em que: $\mathrm{PB}(\% \mathrm{MS})=\%$ de proteína bruta do alimento; $\mathrm{CHO}(\% \mathrm{MS})=\%$ de carboidratos do alimento; EE $(\% \mathrm{MS})=\%$ de extrato etéreo do alimento; CINZA ( $\% \mathrm{MS})=\%$ de cinzas do alimento; FDN $(\% \mathrm{MS})=\%$ de fibra detergente neutro do alimento; PIDN (\% MS) = \% de proteína insolúvel em detergente neutro; LIGNINA $(\% \mathrm{FDN})=\%$ de lignina na FDN do alimento; AMIDO $(\% \mathrm{CNE})=\%$ de amido nos carboidratos não-estruturais do alimento; $\mathrm{CA}(\% \mathrm{CHO})=\%$ do carboidrato do alimento (açúcar $) ; \mathrm{CB} 1(\% \mathrm{CHO})=\%$ do carboidrato do alimento $($ amido + PSN $*) ; \mathrm{CB} 2(\% \mathrm{CHO})=\%$ do carboidrato do alimento (fibra disponível); $\mathrm{CC}(\% \mathrm{CHO})=\%$ do carboidrato do alimento (indisponível); $\mathrm{CCNE}$ $(\% \mathrm{CHO})=\%$ do carboidrato do alimento (não-estrutural).

* Polissacarídeos não-estruturais (pectina, galactina, frutanas, betaglucanos etc)

\section{Resultados e Discussão}

Foram encontrados efeitos significativos de cultivares $(\mathrm{P} \leq 0,00 ; \mathrm{P} \leq 0,00$ e $\mathrm{P} \leq 0,00)$, material $(\mathrm{P} \leq 0,00$; $\mathrm{P} \leq 0,00$ e $\mathrm{P} \leq 0,00)$ e período de armazenamento $(\mathrm{P} \leq 0,00 ; \mathrm{P} \leq 0,00$ e $\mathrm{P} \leq 0,03)$, respectivamente, para as frações $\mathrm{A}, \mathrm{B}_{1}$ e $\mathrm{B}_{2}$ e materiais $(\mathrm{P} \leq 0,00)$ e período de armazenamento $(\mathrm{P} \leq 0,00)$ para a fração $\mathrm{C}$.

A Figura 1 apresenta o efeito do tempo de armazenamento, sobre a fração A, da casca e polpa desidratada, independente da cultivar. Houve aumento nos teores dos açúcares, à medida que aumentou o tempo de armazenamento. Esse aumento foi de 47,5\% ao longo dos 360 dias de armazenamento.

Aumento no teor de açúcar em decorrência do tempo de armazenamento, segundo BARCELOS (2000), pode ser devido à decomposição natural nos tecidos da casca e polpa, principalmente carboidratos

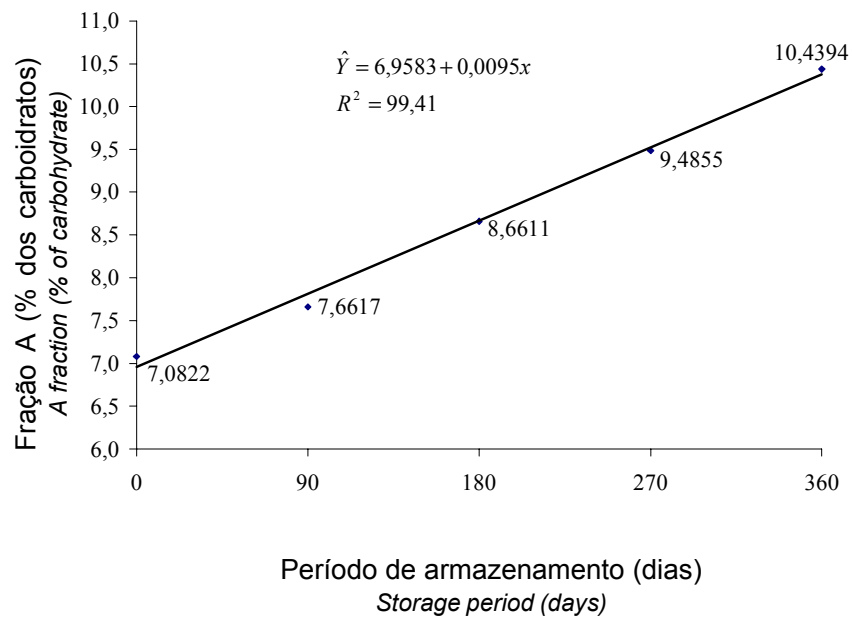

Figura 1 - Efeito do período de armazenamento na fração A (\% dos carboidratos) da casca e polpa de café.

Figure 1 - Effect of the storage period in the $A$ fraction (\% of carbohydrate) of the hull and pulp of coffee. 
estruturais, disponibilizando a fração solúvel. A decomposição natural da parede celular poderia disponibilizar mono e dissacarídeos que seriam os açúcares. Isto levaria também à redução das frações $\mathrm{B}_{2}$ e C, com o tempo de armazenamento (Figuras 3 e 4). Considerando este aspecto, o armazenamento da casca e polpa desidratada de café é importante para reduzir a fração fibrosa e não degradável e disponibilizar açúcares prontamente solúveis, para os microorganismos do rúmen.

A fração $B_{1}$ da casca e polpa desidratada de café das cultivares aumentou $(\mathrm{P} \leq 0,00)$ com o tempo de armazenamento (Figura 2). Embora o valor dessa fração seja baixo, o aumento foi de $37,7 \%$ após 360 dias de armazenamento. Baixos valores para esta fração são decorrentes do baixo teor de amido que neste estudo foi, em média, de $2 \%$ dos carboidratos.

A fração $\mathrm{B}_{2}$ decresceu $(\mathrm{P} \leq 0,03)$ com o tempo de armazenamento (Figura 3). Essa redução representou $3,7 \%$ da fração em 360 dias de armazenamento.

Essa fração, segundo SNIFFEN et al. (1992), é de degradação lenta e corresponde à parede celular disponível. Na casca e polpa de café, esses valores são expressivos (Tabelas 1 e 2) se comparados ao capimelefante com 45 dias (LANNA et al., 1996), que apresenta valor médio de 42,3\%. Assim, aproximadamente $67,0 \%$ dos carboidratos da casca e da polpa de café são de carboidratos de degradação lenta.

Diminuição na fração $\mathrm{B}_{2}$ coincide com o aumento nas frações $A$ e $B_{1}$ destes materiais, o que vem

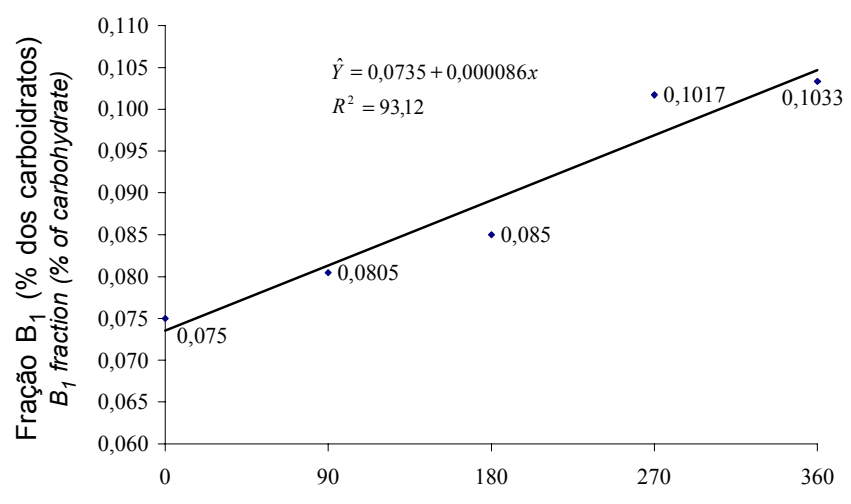

Período de armazenamento (dias) Storage period (days)

Figura 2 - Efeito do período de armazenamento na fração $B_{1}$ (\% dos carboidratos) da casca e polpa de café.

Figure 2 - Effect of the storage period in the $B_{1}$ fraction $(\%$ of carbohydrate) of the hull and pulp of coffee. reforçar a idéia de provável decomposição natural da parede celular, devido ao tempo de armazenamento, que foi relativamente grande. Essa decomposição estaria liberando partes da parede celular de forma solúvel, contribuindo para o aumento, principalmente da fração A de alta disponibilidade.

$\mathrm{Na}$ literatura não foram encontradas informações sobre essas frações na casca e polpa de café, dificultando maior discussão sobre os dados, a não ser comparações com outros materiais fibrosos.

Outra fração de carboidratos importante na avaliação de alimentos para ruminantes é a fração C, por ser a parte indisponível da parede celular. Esta fração não está disponível aos microorganismos do rúmen e para a digestão nos intestinos.

A fração $\mathrm{C}$ da casca e polpa de café sofreu efeito do período de armazenamento $(\mathrm{P} \leq 0,00)$ (Figura 4). A redução da fração indisponível reduziu em 7,5\% no decorrer dos 360 dias de armazenamento. A exemplo da fração $\mathrm{B}_{2}$, a fração $\mathrm{C}$ pode ter sofrido decomposição natural da parede celular indisponível, ao longo do armazenamento e, com isso, contribuir para o aumento da fração A, de maior solubilidade.

Valores elevados para a fração indisponível não limitam totalmente a utilização desses materiais na alimentação de ruminantes. Contudo, ao se recomendá-los, tal fato deve ser considerado.

A variedade Catuaí apresentou maior valor para a fração A. Comparada ao Rubi e Mundo Novo, esta diferença chegou a $28 \%$, a favor da Catuaí, em relação

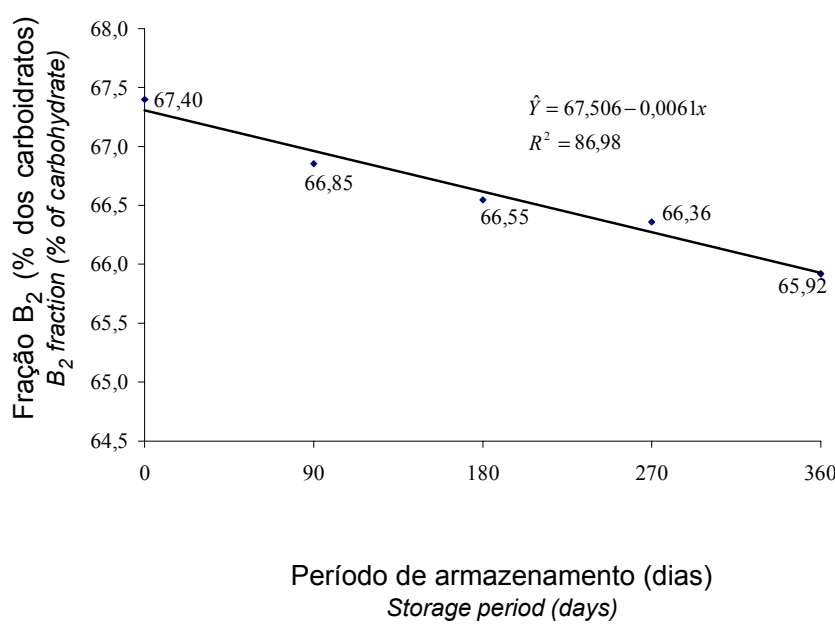

Figura 3 - Efeito do período de armazenamento na fração $\mathrm{B}_{2}$ (\% dos carboidratos) da casca e polpa de café.

Figure 3 - Effect of the storage period in the $B_{2}$ fraction $(\%$ of carbohydrate) of the hull and pulp of coffee. 


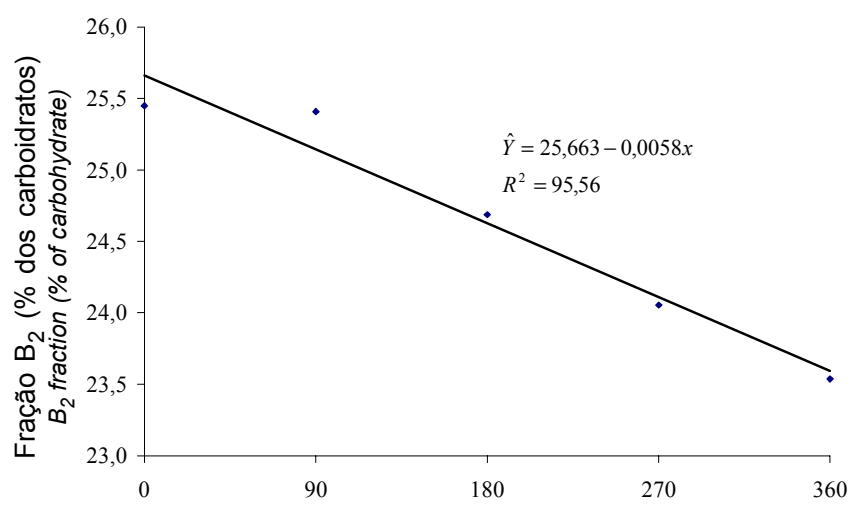

Período de armazenamento (dias) Storage period (days)

Figura 4 - Efeito do período de armazenamento na fração C(\% dos carboidratos) da casca e polpa desidratada de café.

Figure 4 - Effect of the storage period in the $C$ fraction (\% of carbohydrate) of the hull and pulp of coffee.

a Mundo Novo (Tabela 1), indicando que, em relação aos açúcares, a Catuaí é melhor que a Rubi e Mundo Novo.

A fração $B_{1}$ foi maior nas cultivares Catuaí e Rubi, comparadas à Mundo Novo, como pode ser observado na Tabela 1. Os valores para essa fração nas cultivares são baixos, inferiores a $1 \%$, indicando baixo teor de amido e carboidratos de degradabilidade intermediária.

A cultivar Mundo Novo apresentou maior valor $(\mathrm{P} \leq 0,00)$ para a fração $\mathrm{B}_{2}$ comparada às cultivares Catuaí e Rubi (Tabela 1), sendo $2 \%$ em relação à

Tabela 1 - Participações percentuais das frações dos carboidratos, na casca e polpa desidratada de três cultivares de café (\% dos carboidratos totais)

Table 1 - Percent participations of the carbohydrates fractions, in the hull and dehydrated pulp of three coffee cultivars (\% of the total carbohydrates)

\begin{tabular}{lcccc}
\hline Cultivares & \multicolumn{4}{c}{ Frações (\% dos carboidratos totais) } \\
& \multicolumn{4}{c}{ Fractions (\% of the total carbohydrates) } \\
\cline { 2 - 5 } & $\mathrm{A}$ & $\mathrm{B}_{1}$ & $\mathrm{~B}_{2}$ & $\mathrm{C}$ \\
\hline Catuai & $9,75^{\mathrm{a}}$ & $0,098^{\mathrm{a}}$ & $66,02^{\mathrm{b}}$ & $24,26^{\mathrm{a}}$ \\
Rubi & $8,65^{\mathrm{b}}$ & $0,092^{\mathrm{a}}$ & $66,45^{\mathrm{b}}$ & $24,76^{\mathrm{a}}$ \\
Mundo Novo & $7,59^{\mathrm{c}}$ & $0,077^{\mathrm{b}}$ & $67,37^{\mathrm{a}}$ & $24,86^{\mathrm{a}}$ \\
\hline CV $(\%)$ & 19,20 & 22,54 & 2,11 & 5,38 \\
\hline
\end{tabular}

Nas colunas médias seguidas de letras diferentes diferem pelo teste de Scott \& Knott a $5 \%$ de probabilidade.

Means in the columns followed by different letters differ for Scott \& Knott test at $5 \%$ of probability.
Catuaí e 1,4\% em relação à Rubi. Tal fato deve ser uma característica genética inerente a cultivar. Assim, a cultivar Mundo Novo apresenta maior proporção de parede celular em relação a Catuaí e Rubi.

Não foi encontrada diferença significativa entre as cultivares na fração $\mathrm{C}$, mostrando que, quanto aos teores de parede celular indisponível, as cultivares estudas apresentam valores semelhantes e altos, comparados ao valor de $4,5 \%$ para o capim-elefante com 45 dias de idade (LANNA et al., 1996).

A comparação entre materiais mostrou diferença entre casca e polpa desidratada (Tabela 2). A casca de café apresenta maior valor para a fração rapidamente solúvel (A), comparada à polpa desidratada. Tal fato pode ser decorrente da forma de obtenção dos materiais. A casca é obtida da limpeza do café em coco e possui as frações de açúcares, enquanto a polpa é obtida por processo úmido, no qual é lavada antes de sair do despolpador, ocorrendo remoção dos açúcares solúveis. Decorrente deste fato, a fração $\mathrm{B}_{2}$, conseqüentemente, será maior na polpa em relação à casca (Tabela 1), uma vez que as frações são proporcionais em relação ao teor de carboidrato total.

$\mathrm{Na}$ Tabela 2 estão apresentados os valores para as frações $A, B_{1}, B_{2}$ e $C$ segundo os materiais. A casca de café apresenta valor significativamente mais alto para a fração $\mathrm{B}_{1}$, se comparada à polpa desidratada. Mesmo sendo os valores tão baixos a diferença foi $47 \%$ maior na casca de café. Isto pode ser explicado pela solubilização desta fração no processo de obtenção da polpa, como ocorrido na fração A, ou seja, parte da fração amido e pectina pode ter sido solubilizada pela água no processo de despolpa

Tabela 2 - Participações percentuais das frações dos carboidratos da casca e polpa desidratada, de três cultivares de café (\% dos carboidratos totais)

Table 2 - Percent participations of the carbohydrates fractions in the hull and dehydrated pulp of three coffee cultivars (\% of the total carbohydrates)

Cultivares $\quad$ Frações (\% dos carboidratos totais)

Cultivars Fractions (\% of the total carbohydrates)

\begin{tabular}{lcccc} 
& $\mathrm{A}$ & $\mathrm{B}_{1}$ & $\mathrm{~B}_{2}$ & $\mathrm{C}$ \\
\hline Casca & $10,10^{\mathrm{a}}$ & $0,106^{\mathrm{a}}$ & $65,79^{\mathrm{b}}$ & $23,83^{\mathrm{b}}$ \\
Hull & & & & \\
Polpa & $7,23^{\mathrm{b}}$ & $0,072^{\mathrm{b}}$ & $67,44^{\mathrm{a}}$ & $25,43^{\mathrm{a}}$ \\
Pulp & & & & \\
\hline CV (\%) & 19,20 & 22,54 & 2,11 & 5,38 \\
\hline
\end{tabular}

Nas colunas médias seguidas de letras diferentes diferem pelo teste de Scott \& Knott a $5 \%$ de probabilidade.

Means in the columns followed by different letters differ for Scott \& Knott test at $5 \%$ of probability. 
do café. O teor dessa fração na casca e polpa desidratada de café é baixo e, na prática, terá pouca influência nos parâmetros cinéticos ruminais.

A fração indisponível (C) para os ruminantes foi maior na polpa em comparação à casca de café (Tabela 2), decorrente de menor valor da fração solúvel (A) da polpa. A proporção segue o mesmo princípio da fração $\mathrm{B}_{2}$, no qual a redução ou aumento em uma fração aumenta ou reduz a outra. Os valores desta fração podem ser considerados altos, uma vez que $24 \%$ dos carboidratos estão indisponíveis. Isto pode limitar o aproveitamento desses materiais, para ruminantes.

Há necessidade de também se estudar o fracionamento da proteína, para completar as informações sobre o potencial da casca e polpa como alimento para ruminantes.

\section{Conclusões}

O armazenamento por doze meses alterou a proporção dos carboidratos, reduzindo as frações de degradabilidade lenta e não degradável, favorecendo as frações de degradabilidade rápida.

A casca e polpa de café são materiais com alta proporção de carboidratos indisponíveis para ruminantes, o que pode limitar o seu uso em grandes quantidades na dieta destes animais.

A cultivar Mundo Novo apresentou maior teor de carboidratos de degradabilidade lenta $\left(\mathrm{B}_{2}\right)$ e menor teor de carboidratos rapidamente degradáveis, que as cultivares Catuaí e Rubi.

\section{Referências Bibliográficas}

BARCELOS, A.F. Parâmetros bromatológicos, frações de carbidratos e degradabilidade in vitro da casca e da polpa de café (Coffea arabica L.). Lavras: UFLA, 2000, 96p. (Doutorado em Zootecnia) - Universidade Federal de Lavras. FLORIANI, C.G. Café - A certificação é o caminho. Caderno Técnico $\mathrm{n}^{\mathrm{o}}$ 1, IMA, 2000, 20p.
LANNA, D.P.D., FOX, D.G., BALSALOBRE, M.A.A. et al. Utilização da metodologia de análise de alimentos do CNCPS e do sistema de produção de gás in vitro na estimativa do valor nutricional do capim elefante. In: REUNIÃO ANUAL DA SOCIEDADE BRASILEIRA DE ZOOTECNIA, 33, 1966, Fortaleza. Anais... Fortaleza: SBZ, 1966. p.289-291.

PEREIRA, J.R., BOSE, M.L.V., BOIN, C. 1997a. Avaliação das subfrações dos carboidratos e das proteínas, usando as metodologias do CNCPS e in situ com bovinos da raça Nelore. 2. Milho e farelo de algodão. R. Bras. Zootec., 26(4): 838-843.

PEREIRA, J.R.A., BOSE, M.L.V., BOIN, C. 1997b. Avaliação das sub-frações dos carboidratos das proteínas, usando as metodologias do CNCPS e in situ com bovinos da raça Nelore. 1. Silagem de milho. R. Bras. Zootec., 26(4):832-837.

ROSSI JR., P., BOIN, C., BOSE, M.L.V. et al. 1997a. Degradabilidade ruminal da fibra em detergente neutro e do nitrogênio insolúvel em detergente neutro da silagem de milho e do farelo de soja, em bovinos da raça Nelore. R. Bras. Zootec., 26(4):608-615.

ROSSI JR., P., SILVA, A.G., WANDERLEY, R.C. et al. 1997b. Degradabilidade ruminal da matéria seca e da fração protéica da silagem de milho, do farelo de soja e do sorgo em grão, em bovinos da raça Nelore. R. Bras. Zootec., 26(4):599-607.

SNIFFEN, C.J., O'CONNOR, J.D., VAN SOEST, P.J. et al. 1992. A net carbohydrate and protein system for evaluating cattle diets: II. Carbohydrate and protein availability. J. Anim. Sci., 70(11):3562-3577. 